\title{
Estimation of Infiltration Rate (ACH Natural) Using Blower Door Test and Simulation
}

\author{
Junghyon Mun *, Jongik Lee $(D)$ and Minsung Kim
}

Citation: Mun, J.; Lee, J.; Kim, M. Estimation of Infiltration Rate (ACH Natural) Using Blower Door Test and Simulation. Energies 2021, 14, 912. https://doi.org/10.3390/en14040912

Received: 30 December 2020

Accepted: 29 January 2021

Published: 9 February 2021

Publisher's Note: MDPI stays neutral with regard to jurisdictional claims in published maps and institutional affiliations.

Copyright: (c) 2021 by the authors. Licensee MDPI, Basel, Switzerland. This article is an open access article distributed under the terms and conditions of the Creative Commons Attribution (CC BY) license (https:// creativecommons.org/licenses/by/ $4.0 /)$.
Sun \& Light R\&D Center, Seoul 06648, Korea; 4leaflee@greenbim.kr (J.L.); ceo@greenbim.kr (M.K.)

* Correspondence: mjh@greenbim.kr

\begin{abstract}
One of the primary factors for generating heating and cooling loads in apartment houses is infiltration. However, the evaluation method for infiltration rates has not been well established for the apartment houses in Korea. The existing method measures air change per hour of a house at $50 \mathrm{~Pa}(\mathrm{ACH} 50)$ and divides it by the leakage-infiltration ratio, $\mathrm{N}=20$, as suggested by the Lawrence Berkeley National Laboratory (LBL). In this study, a method to evaluate the average infiltration rate of an apartment house using blower door tests and simulations is suggested. Six sets of blower door tests were conducted, and the measurement data were used to estimate the flow coefficients and pressure exponents of all infiltration routes. The values were used as the input data for EnergyPlus to calculate the natural air change per hour values ( $\mathrm{ACHn}$ ) of two households. The calculated $\mathrm{ACHn}$ values were compared to the ACHn values calculated using the LBL method, which is commonly used in Korea. Through this process, the limitations of applying the LBL method to calculate the ACHn values in Korea were investigated. The results show that investigating the proper leakageinfiltration ratio is required for Korea. The method suggested in this study can be used to determine the proper leakage-infiltration ratio for apartment houses.
\end{abstract}

Keywords: blower door test; infiltration; flow coefficient; pressure exponent; crack method; ACHn; EnergyPlus

\section{Introduction}

According to the 2018 population and housing census released by the National Statistical Office in Korea, the population living in apartment houses is greater than half of the total population in South Korea, and it has been increasing every year. According to the census data, there were 10 million apartment houses in Korea, and 39.6\% of them were built more than 20 years ago. One of the factors affecting the heating and cooling loads in apartment houses built more than 20 years ago is the infiltration caused by the pressure difference between the indoor and outdoor environments. Numerous studies related to infiltration have been performed in Korea. However, there is a lack of self-established data that can be used to estimate the infiltration rates of apartments. Therefore, as an essential part of building energy analysis, the infiltration of buildings should be measured by type, and the data should be organized to understand the effects of the characteristics of domestic buildings on infiltration.

The simplest method to determine the infiltration of a building is the air-change method, which uses the number of air changes per hour in the building. The number of air changes per hour can be measured using blower door tests. When the pressure difference between the indoor and outdoor environments is $50 \mathrm{~Pa}$, the air flow rate $\left(\mathrm{m}^{3} / \mathrm{h}\right)$, which creates a pressure difference of $50 \mathrm{~Pa}$, is measured using a blower door test equipment. The air flow rate is divided by the indoor volume of the house, which is referred to as ACH50 (air change per hour at $50 \mathrm{~Pa}$ ). The $\mathrm{ACH} 50$ values were used to evaluate the infiltration level of the houses. However, the amount of infiltration into a building under natural conditions cannot be determined by the ACH50 value because the pressure difference 
between the indoor and outdoor conditions is not $50 \mathrm{~Pa}$ but approximately 1-4 Pa under natural conditions. The air change per hour value under natural conditions is referred to as $\mathrm{ACH}$ or ACHn (ACHnatural), and this is used to calculate the heating and cooling load of a building in building energy simulation programs. The most popular method to estimate ACHn was developed by the Lawrence Berkeley National Laboratory (LBL). The method uses a leakage-infiltration ratio $\mathrm{N}$ to convert $\mathrm{ACH} 50$ to $\mathrm{ACHn}$, as shown in Equation (1).

$$
\mathrm{ACHn}=\mathrm{ACH} 50 / \mathrm{N}
$$

The leakage-infiltration ratio $\mathrm{N}$ can be calculated using the correction factors for the building height, site shielding, and building leakage type. However, it does not apply in all cases. Therefore, the LBL suggests using $\mathrm{N}=20$ conservatively in general cases. In Korea, $\mathrm{N}=20$ has been generally used when converting ACH50 to ACHn. However, research has shown that it may not be suitable to set $\mathrm{N}$ to 20 in Korea [1].

A more accurate method to estimate the infiltration rate of a building is the crack method. The crack method calculates the infiltration rate dependent on a crack, such as a door, window, lighting fixtures, and joint around the floor and wall as well as the pressure difference across the crack derived by the wind, stack effect, and heating, ventilation, and air conditioning systems. The infiltration rate can be calculated using the following equation:

$$
Q=C[\Delta P]^{n}
$$

where $Q$ is the infiltration rate $\left(\mathrm{m}^{3} / \mathrm{h}\right), C$ is the flow coefficient, $n$ is the pressure exponent, and $\Delta P$ is the pressure difference across the crack. The flow coefficient $C$ is the same as the infiltration rate when the pressure difference across the crack is $1 \mathrm{~Pa}$. The pressure exponent $n$ changes based on the nature of the infiltration and typically has a value between 0.6 and 0.8 [2].

In the United States, fundamental research on infiltration was carried out in the 1980s [3,4]. Numerous studies have been conducted in the United States and Europe to measure the tightness of buildings using blower tests [5-11]. There are studies that use regression methods to predict infiltration by analyzing the large amount of data obtained from blower door tests and a database $[12,13]$. Studies have also been conducted to estimate the amount of infiltration and its effect using an air flow network software, such as Contam, and by performing energy simulation based on the blower door test results $[14,15]$.

However, there are few studies on the procedure for calculating the infiltration rate, especially ACHn that is suitable in Korea wherein the apartment house is a common residential type. In Korea, research on infiltration has been carried out since the 2000s. Numerous studies have been conducted to determine the infiltration rate of multi-family housing [16-18]. These studies focus on estimating the infiltration rate through indicators representing the exterior performance of the building, such as ACH50. Undram summarized the existing studies on the measurement of the infiltration level of buildings [19]. In addition, the characteristics of infiltration in multi-family housings using blower door tests have been studied [20].

The objective of this study is to suggest a method to evaluate the infiltration rate, especially ACHn, of apartment houses in Korea using the blower door test. For this purpose, two households were selected to determine the infiltration routes and to estimate the flow coefficient $C$ and pressure exponent $n$ of each infiltration route using blower door tests.

A preliminary measurement was conducted for one week to determine the infiltration routes of the households, and the main measurement was conducted in the following week to estimate the flow coefficients and pressure exponents of the infiltration routes. With the flow coefficients and pressure exponents, the average infiltration rates of the households were calculated using the air flow network module in EnergyPlus. The infiltration calculations were performed for three cities, Seoul, Sejong, and Jeju, representing Korea's three climate zones. Seoul is located in the northern part of Korea. It is the capital city and has 
the largest population in Korea. Sejong is located in the inland area, and it is representing the cities located in the inland province. Jeju is located on an island in the southern part of Korea. It is the warmest city and has the highest wind speed in Korea. The suitability of the leakage-infiltration ratio, $\mathrm{N}=20$, for the infiltration analysis of the apartment houses in Korea was determined from this analysis.

\section{Materials and Methods}

\subsection{Infiltration Measurement}

Flow coefficients $\mathrm{C}$ and pressure exponents $\mathrm{n}$ can be obtained using blower door tests. The blower door test uses a fan to blow air into a house to pressurize the indoor environment or out of the house to depressurize it. The blower door tester measures the static pressure difference between the indoor and outdoor environments and the amount of air blown by the fan, while the pressure difference is varied gradationally between $10 \mathrm{~Pa}$ and $50 \mathrm{~Pa}$. The test data can be expressed as a regression equation using Equation (2). From this equation, the flow coefficient $C$ and pressure exponent $n$ can be determined.

The measurement was conducted in a three-story apartment house located in Sejong, Korea, which was built in 2018 by the Korea Land and Housing Corporation (LH). This apartment house was built for an environmental experiment on apartment houses. Therefore, the apartment house has the same construction and environmental conditions as commercially available apartment houses built by LH. LH has built 2.7 million apartment houses, approximately $30 \%$ of the total number of apartment houses in Korea.

Two households in the apartment were rented for the purpose of measurement, which are indicated as C-201 and C-202 in Figure 1. They are located on the second floor, and the floor plan of the households is provided in Figure 1. The floor area of each household where the measurements were conducted is $52 \mathrm{~m}^{2}$ and the ceiling height is $2.4 \mathrm{~m}$. The exterior wall construction is composed of $100 \mathrm{~mm}$ concrete and $145 \mathrm{~mm}$ cellular polystyrene insulation. The inner surface of the wall is finished with wallpaper. There is only one type of window in the households. It is an aluminum low-e double-glazed window with a glass thickness of $6.4 \mathrm{~mm}$ and an air layer of $6.4 \mathrm{~mm}$. The exterior door is a glade A fire door, which adheres to the standards specified by the law to be used in the apartment houses in Korea. Regular maintenance of these households is conducted by LH. Therefore, the condition is relatively better than the actual apartment houses. The floor plans of the two households are the same and symmetrical to each other. The three surfaces of each household face the outsides. C-201 has the south side, the north side, and the west side facing the outside. C-202 has the south side, the north side, and the east side facing the outside.

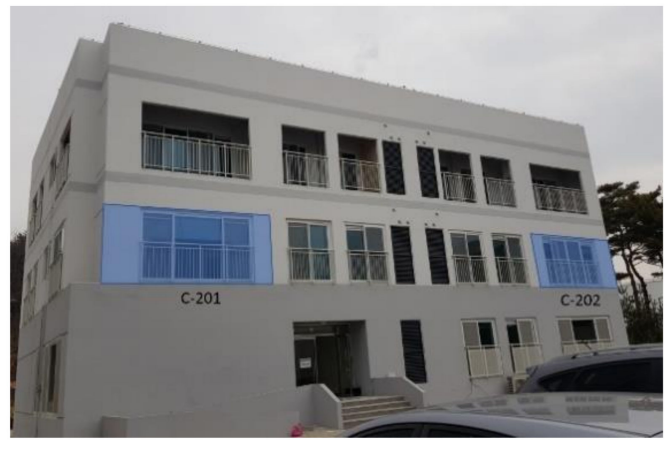

Front view



Floor plan

Figure 1. Floor plan and direction of the apartment house.

The blower door tester used in this study was KNS-4000C made by the Sapporo company in Japan. It is designed for residential house infiltration test and can be installed on a door frame or a window frame. The maximum flow rate of the blower door tester is $60 \mathrm{~m}^{3} / \mathrm{min}$, and it starts to work when the pressure difference between the indoor and 
outdoor becomes $10 \mathrm{~Pa}$ and stops when the pressure difference becomes approximately $50 \mathrm{~Pa}$. For calibration, 10 sets of measurements were carried out for two days. During this process, the flow rate and pressure difference variation were measured using other sensors, and the results were compared to the data from the blower door test. The average error rate of 10 sets was within $5 \%$. During the blower door test period, the indoor air temperature was measured to be $18-19{ }^{\circ} \mathrm{C}$ and the outdoor temperature was $11-14^{\circ} \mathrm{C}$. The blower door tests were conducted when the outdoor wind speed was less than $1 \mathrm{~m} / \mathrm{s}$.

The preliminary measurement was conducted from 3 June 2019 to 7 June 2019 to determine the measurement points for the main measurement. In the preliminary test, the infiltration rate was measured using a blower door tester without air sealing. The next blower door test was conducted after sealing the area through which infiltration was expected to occur. By repeating this process, six cases were selected as the infiltration routes for the main measurement.

The main measurement was conducted in the two households from 3 June 2019 to 7 June 2019 for the six cases selected in the preliminary measurement. In the first measurement case, all possible infiltration routes were sealed using airtight tape and membranes. The amount of infiltration was determined through unknown routes. After the completion of the first measurement, the remaining five cases were tested by sequentially removing the sealing tape and membranes. In the second case, measurements were conducted after removing the airtight tape and membranes from the south windows. In the third case, measurements were conducted after removing the airtight tape and membranes sealing the entire kitchen and duct pipe connected to the kitchen. The extent of infiltration through the entire kitchen and duct pipe connected to the kitchen had to be determined. In the fourth case, measurements were conducted after removing the airtight tape from the wall sockets and lighting fixtures distributed throughout the entire household. In the fifth case, measurements were obtained after removing the airtight tape from the west windows in C-201 (east windows in C-202). In the last case, measurements were conducted after removing the airtight tape and membranes from the north windows. The removal sequence of the airtight tape and membranes is shown in Figures 2 and 3.
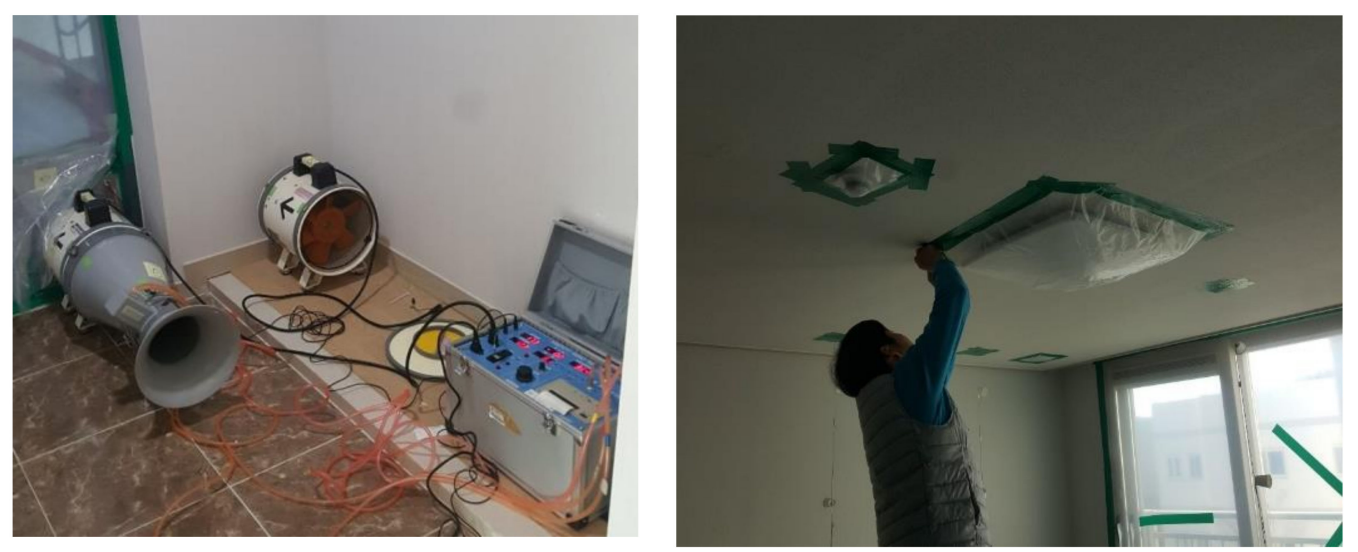

Figure 2. Blower door tester and sealing work in the household. 


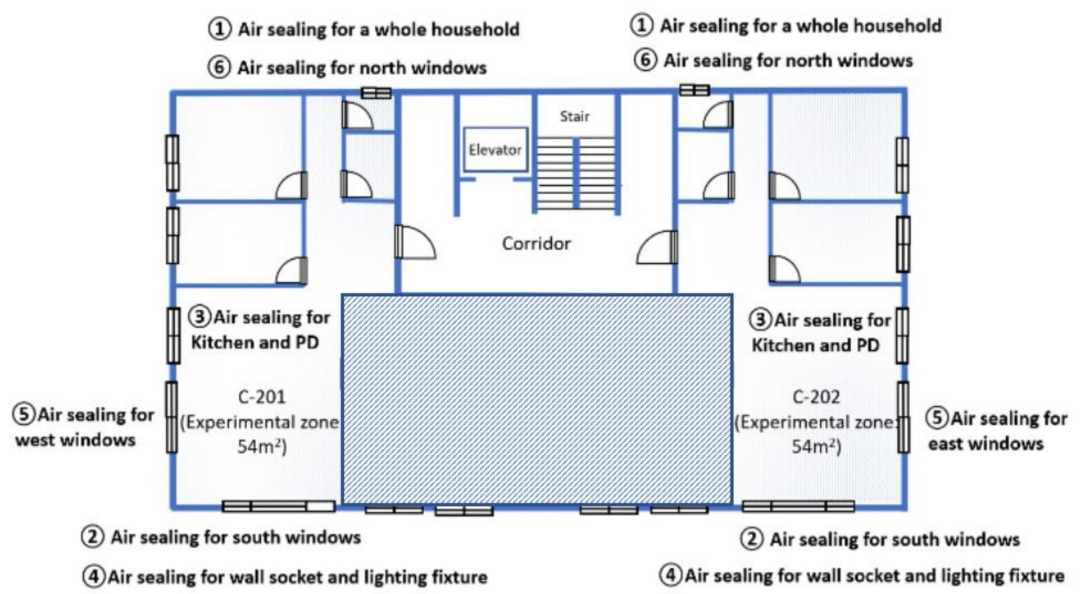

Figure 3. Removal sequence of the air tight tapes and membranes from the infiltration routes.

\subsection{Infiltration Data Processing}

The blower door test results for C- 201 are shown in Figure 4. The test was carried out using the depressurization method. The blow door tester automatically starts the measurement when the pressure difference is approximately $20 \mathrm{~Pa}$. The air flow rate that increases the pressure difference at $10 \mathrm{~Pa}$ intervals until the pressure difference reaches $60 \mathrm{~Pa}$ was measured.



Figure 4. Blower door test data for the six measurement conditions.

The horizontal axis of the graph in Figure 4 is the change in the pressure difference $(\mathrm{Pa})$, and the vertical axis is the flow rate $\left(\mathrm{m}^{3} / \mathrm{h}\right)$, creating the pressure change. The measured data in Figure 4 can be expressed in the form of Equation (2). However, they were modified to a simple linear regression form by adding $\log 10$ to the right and left terms. Thus, the flow coefficient $C$ and pressure exponent $n$ can be easily determined for each case. Using the modified equations, the flow rate differences between each case were found. The relationship between the pressure difference and flow rate difference between each case is shown in Figure 5. In cases other than Q3-Q2, the flow rate profiles according to the pressure difference are similar and overlap, as shown in Figure 5. 


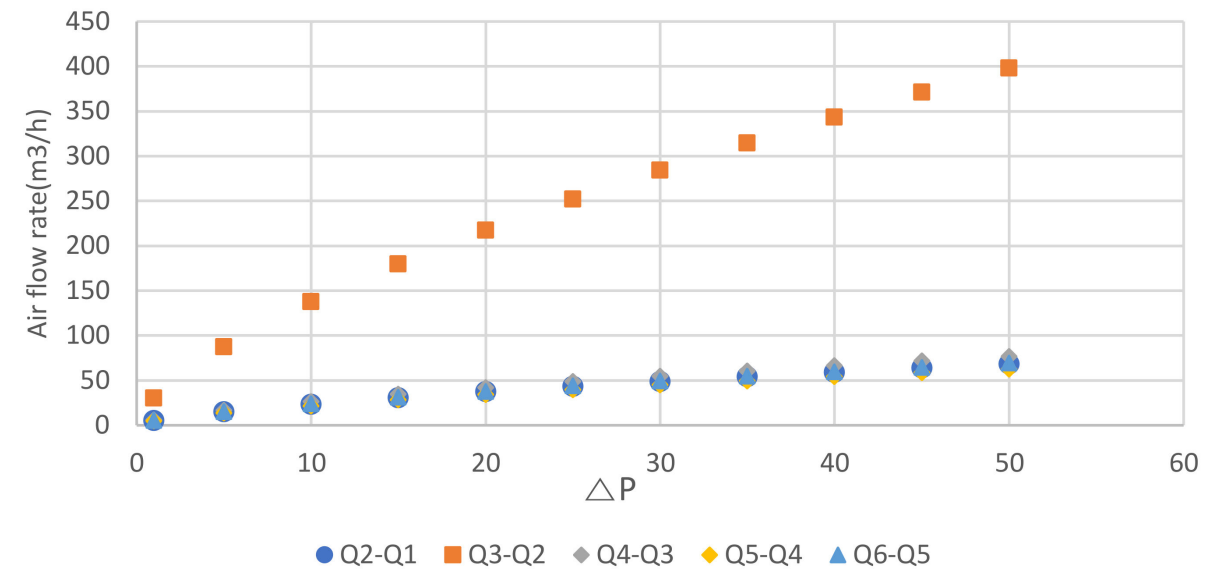

Figure 5. Air flow rate difference with various pressure differences through the infiltration routes.

The flow rate through the south windows $(\mathrm{Q} 2-\mathrm{Q} 1)$ dependent on the pressure difference was determined by subtracting the flow rate (Q1) measured when the entire household was sealed from the flow rates $(\mathrm{Q} 2)$ measured when the sealing material was removed from the south windows. Using the relationship between the flow rate, Q2-Q1, and the pressure difference variation, a simple linear regression equation was generated. From this equation, the flow coefficient $C$ and pressure exponent $n$ for the infiltration through the south window can be estimated. Using this method, the flow coefficients and pressure exponents for all the other infiltration routes were estimated.

In Figure 5, Q2-Q1 indicates the flow rate through the south windows as the pressure difference changes. Q3-Q2 is the flow rate through the kitchen and duct pipe connected to the kitchen. Q4-Q3 is the flow rate through the wall sockets and lighting fixtures installed throughout the entire household. Q5-Q4 is the flow rate through the west windows in C-201 (east window in C-202). Q6-Q5 is the flow rate through the north windows.

In addition, the values of ACH50 for C-201 and C-202 were measured directly using the blower door test. The ACH50 values measured for C-201 and C-202 using the blower door test at 50 Pa were 6.14 and 8.07, respectively.

\section{Results}

This section describes the estimation method for the infiltration performance of each infiltration route using the blower door test data and the calculation method for the infiltration rate of a household using the blower door test results.

\subsection{Infiltraion Performance Analysis for Each Infiltraion Route}

\subsubsection{Preliminary Analysis}

Preliminary analysis was carried out to determine the optimal data analysis method for determining the flow coefficients and pressure exponents for all infiltration routes using the blower door test data. The analysis methods were determined based on a study that measured interzonal leakage using blower door techniques [21,22]. The existing methods were composed of a simple method that uses one measured value at a constant pressure, and a detailed method that uses linear equations and an iterative method that determines the flow coefficients and pressure exponents for interzonal leakage. In this process, we investigated whether the regression equations for all the six test cases could be determined without an iterative process using the least squares method, and we found that the $R^{2}$ values of all the regression equations should be the maximum. Using the blower door test results from the six test cases, the regression equations for the air flow rate difference dependent on the pressure difference $\left(Q_{m}-Q_{m-1}: m\right.$ is the case number $)$ were determined. The flow coefficients and pressure exponents determined from the regression equations are listed in Table 1. 
Table 1. Infiltration coefficient calculation result using the least square method.

\begin{tabular}{ccccccc}
\hline C-201 & Q1 & Q2-Q1 & Q3-Q2 & Q4-Q3 & Q5-Q4 & Q6-Q5 \\
\hline $\mathrm{n}$ & 0.687 & 0.548 & 0.643 & 0.773 & 0.677 & 0.420 \\
$\mathrm{C}$ & 13.766 & 7.826 & 31.929 & 3.920 & 4.454 & 27.222 \\
\hline
\end{tabular}

In Table 1, the pressure exponent $(n)$ of the sixth case $\left(Q_{6}-Q_{5}\right)$ is less than 0.5. This is not physically reasonable because $\mathrm{n}$ must be between 0.5 and 1 . When there is a laminar flow along a very long channel with a pressure difference of $\Delta, \mathrm{n}$ is 1 . As the channel narrows, the laminar flow develops into a turbulent flow. During this process, the value of $\mathrm{n}$ gradually decreases and becomes $1 / 2$ when the flow becomes completely turbulent. Therefore, $n$ should be larger than 0.5 [2]. Therefore, this method is not suitable for determining the flow coefficients and pressure exponents.

In existing studies, the $C$ and $n$ values are determined using the Monte Carlo method and regression equations with iterations [21,22]. Instead of the Monte Carlo method, the entire investigation was used in this study to determine the suitability of determining the $C$ and $\mathrm{n}$ values of the infiltration routes. The conditions required for the main analysis were investigated. By changing $\mathrm{n}$ gradually, six regression equations for the six measurement cases and five regression equations for the flow rate differences $\left(Q_{m}-Q_{m-1}: m\right.$ is the case number) were estimated. From the set of equations, the pressure exponents and flow coefficients that provided the maximum average $R^{2}$ value of the five regression equations were selected. The $R^{2}$ values of all the regression equations were calculated as the $n$ value changed by 0.01 within the range of 0.60 to 0.80 .

One of the criteria found through the analysis is that the $n$ value for the subsequent case should be larger than or equal to that of the current case. This is because the crack size increases as the measurement progresses owing to the removal of additional sealing tape and membranes from the crack. If the $n$ value of the subsequent case is smaller than that of the current case, the infiltration rate of the subsequent case may be smaller than that of the current case from a specific pressure as the pressure difference increases. Therefore, the main analysis was conducted based on the criterion that the $\mathrm{R}^{2}$ value of each regression equation should be greater than 0.9 , and the $\mathrm{n}$ value of the subsequent case should be greater than or equal to that of the current case for the regression equations obtained from the blower door tests.

\subsubsection{Main Analysis}

The main analysis was carried out based on the preliminary analysis. The analysis process is shown in Figure 6. In Figure 6, the subscript $m$ is for the blower door test cases, and it increases from 1 to 6 . The subscript $r$ is for the calculated cases using the air flow rate difference $\left(Q_{m}-Q_{m-1}: m\right.$ is the case number). For the criteria located at the middle of the flow chart, the $R^{2}$ value of each regression equation should be greater than 0.9 , and the $n$ value of the subsequent case should be larger than or equal to that of the current case. If the criteria are not met, the calculation is stopped, and the next calculation is performed. For the criterion located at the bottom of the flow chart, $\mathrm{R}^{2}$ should be 0.9 . This serves to reduce the calculation time. The calculation time was $8 \mathrm{~h}$ without the criteria and was reduced to within 5 min with the criteria (Execution program: Matlab 2019, Execution hardware: Intel Core i7-7700 CPU, 8 GB RAM).

The analysis results using this process are listed in Table 2. In Table 2, the $\mathrm{n}$ value required to obtain the maximum average value of $R^{2}$ is 0.65 for $C-201$. For C-202, the $n$ value was calculated to be 0.67 . 


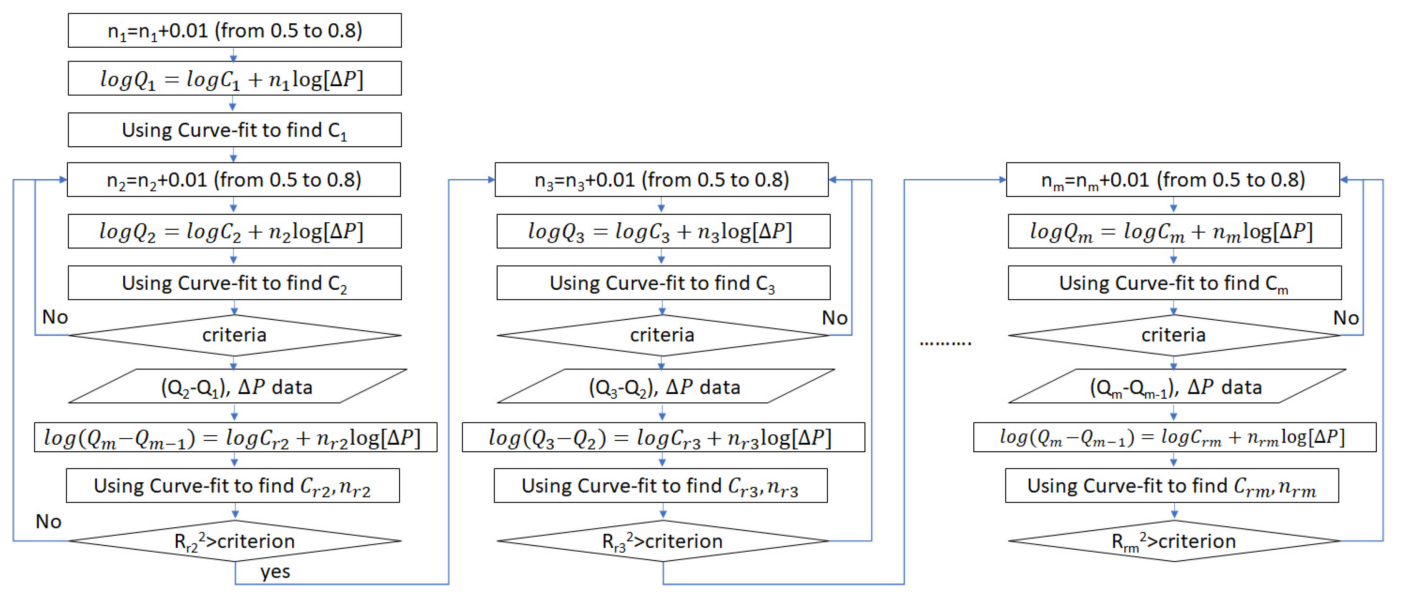

Figure 6. Analysis method for estimating the flow coefficients and pressure exponents.

Table 2. Infiltration coefficient calculation result from blower door test $(\mathrm{kg} / \mathrm{s})$.

\begin{tabular}{ccccccc}
\hline & $\begin{array}{c}\text { Infiltration through } \\
\text { Unknown Routes }\end{array}$ & $\begin{array}{c}\text { Infiltration } \\
\text { through South } \\
\text { Windows }\end{array}$ & $\begin{array}{c}\text { Infiltration } \\
\text { through Kitchen } \\
\text { and PD }\end{array}$ & $\begin{array}{c}\text { Infiltration through } \\
\text { Wall Sockets and } \\
\text { Lighting Fixtures }\end{array}$ & $\begin{array}{c}\text { Infiltration } \\
\text { through Side } \\
\text { Windows }\end{array}$ & $\begin{array}{c}\text { Infiltration } \\
\text { through North } \\
\text { Windows }\end{array}$ \\
\hline $\mathrm{C}-201$ & 0.00488 & 0.00166 & 0.00966 & 0.00186 & 0.00150 & 0.00379 \\
$\mathrm{C}-202$ & 0.00593 & 0.00141 & 0.01320 & 0.00109 & 0.00094 & 0.00188 \\
\hline
\end{tabular}

\subsection{Infiltraion Rate (ACHn) Estimation}

The airflow network module in EnergyPlus was used to estimate the infiltration rates through the infiltration routes using the $C$ values and $n$ values of the routes. The airflow network is an infiltration calculation module based on Airnet, developed by NIST. The input data for infiltration in EnergyPlus were created by constructing the infiltration routes, as shown in Figure 7. The infiltration routes connecting the outdoor and indoor environments were set as follows: the infiltration route through the south windows, infiltration route through the north windows, infiltration route through the west windows for C-201 (east windows for C-202), and infiltration route through the kitchen and duct pipe connecting the indoor and outdoor environments. There are two infiltration routes where the measurements show that infiltration occurs; however, the location of infiltration is not specified. These routes are the cracks around the wall sockets and lighting fixtures distributed evenly in the household and the infiltration measured after sealing the entire household.

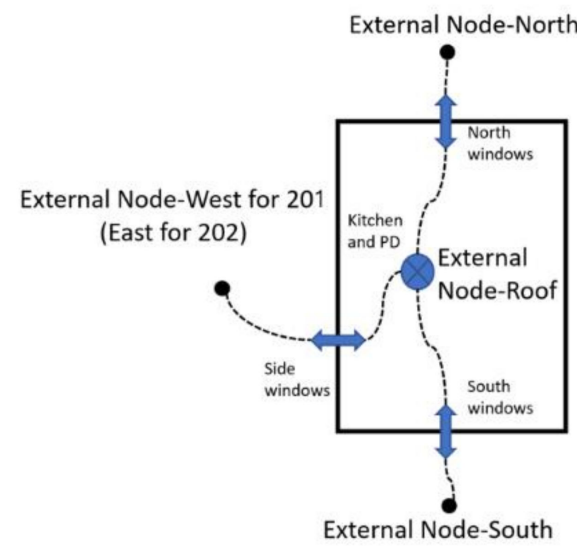

Figure 7. Infiltration route description of the air flow network in EnergyPlus.

The ratio of the infiltration rate through each infiltration route to the total infiltration rate can be obtained using the $C$ value in Table 2 . The infiltration measured after sealing 
the entire household is approximately $21 \%$ of the total infiltration for C-210 and $24 \%$ of the total infiltration for C-202. The infiltration through the cracks around the wall sockets and lighting fixtures is approximately $14 \%$ of the total infiltration for C-210 and $8 \%$ of the total infiltration for C-202. In conclusion, the ratio of the infiltration for which the infiltration route cannot be specified to the total infiltration was 35\% and 32\% for C-201 and C-202, respectively. Therefore, infiltration through these two infiltration routes is the biggest factor causing uncertainty in the simulation. The calculation result changes depending on how the infiltration through these two infiltration routes is reflected in the simulation.

While changing the distribution ratio of infiltration for which the infiltration route cannot be specified in the south windows, north windows, and west windows for C-201 (east for C-202), the conditions providing the maximum and minimum average infiltration rates in the household were investigated. The tool used in this parametric analysis was JEPlus, which is used for EnergyPlus parametric analysis. Figure 8 shows how the input data are changed in the parametric analysis in JEPlus. In Figure 8, $\mathrm{Ck}$ is the flow coefficient for the kitchen and duct pipe; $\mathrm{Cs}$ is the flow coefficient for the north windows; $\mathrm{Cw}$ is the flow coefficient for the west windows for C-201 (east windows for C-202); $C_{N}$ is the flow coefficient for north windows; $\alpha, \beta, \curlyvee$, and $\theta$ are the values obtained by distributing the fluid coefficient $C$ value of the infiltration for which the infiltration route cannot be specified. The sum of them is $\varepsilon$, and they are added to the $C$ value of each route in Figure 7 . When distributing these values to each infiltration route in JEPlus, the input data were changed while increasing the fluid coefficient of each infiltration route by the value of $\varepsilon / n$.

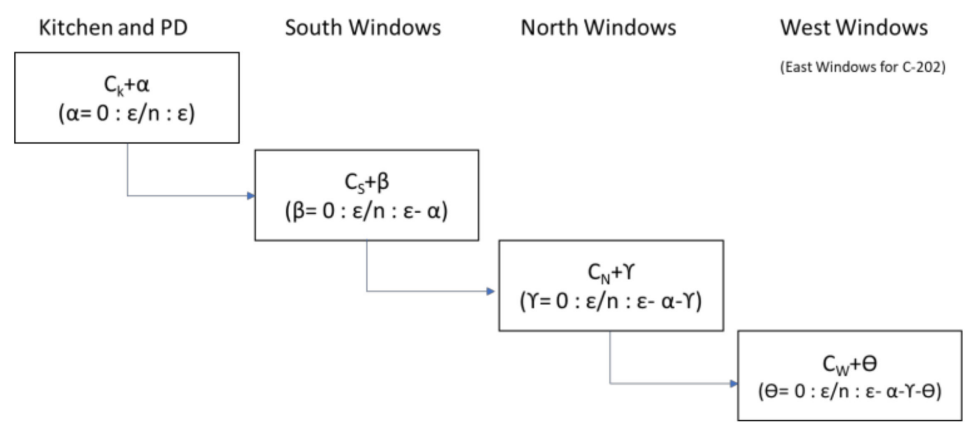

Figure 8. Parametric analysis process using JEPlus.

Figure 9 shows the analysis results when $\mathrm{n}$ is set to 5 . In this case study for $\mathrm{C}-201, \mathrm{Ck}$ is 0.00966 ; $\mathrm{Cs}$ is $0.00488 ; \mathrm{C}_{\mathrm{N}}$ is $0.00379 ; \mathrm{CW}$ is 0.00150 ; and $\varepsilon$, the sum of the fluid coefficients for the infiltration for which the infiltration route cannot be specified, is 0.00674 . In the case study, $\alpha, \beta, \curlyvee$, and $\theta$ change in increments of 0.00135 , which is the value of $\varepsilon$ divided by 5 . They are added to the fluid coefficient of each infiltration route, and their sum should be $\varepsilon$ at every calculation step.

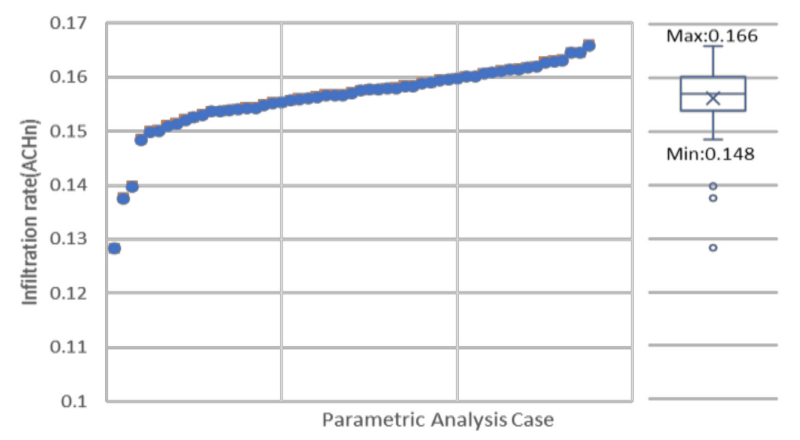

Figure 9. Natural air change per hour values $(\mathrm{ACHn})$ calculation result using the parametric analysis. 
The left side of Figure 9 shows the results sorted according to the size of the calculation values, and the right side shows the distribution diagram of the analysis results as a box plot. Outliers in the box plot occur when all the values of $\varepsilon$ are added to the flow coefficient $\mathrm{Ck}$, and when $80 \%$ of the $\varepsilon$ values are added to the flow coefficient $\mathrm{Ck}$. The probability of occurrence of outliers was calculated as 3/55 in this perimetric analysis. The maximum and minimum values indicated by the box plot were $0.166 \mathrm{ACHn}$ and $0.148 \mathrm{ACHn}$, respectively, and the average value was $0.158 \mathrm{ACH}$.

To investigate where the outdoor air enters and the indoor air exits, the infiltration rate and exfiltration rate through each route were calculated when the average infiltration rate was $0.158 \mathrm{ACHn}$ in C-201 and C-202.

In this case, 0.001348 is added to Ck, Cs, and Cw. A value of 0.002696 is added to $\mathrm{CN}$ for the north windows. Figure 10 shows the average infiltration rates and average exfiltration rates through each route for C-201 and C-202. As shown in Figure 10, outdoor air enters through the windows on the three sides and is discharged to the outside through the kitchen and duct pipe. The floor area of the household was $54 \mathrm{~m}^{2}$, and the ceiling height was $2.4 \mathrm{~m}$. Therefore, the indoor volume of the household was calculated to be $129.6 \mathrm{~m}^{3}$. The ACHn value of each household can be calculated by dividing the sum of infiltration from the outside or sum of exfiltration to the outside in Figure 7 by the indoor volume of the household. There was a difference in the infiltration rate through each infiltration route in C-201 and C-202; however, the calculated average infiltration rate was the same value of $0.158 \mathrm{ACHn}$ in both the households. As a result of the uncertainty analysis, the average infiltration rate was calculated when the $C$ value of the uncertain infiltration route was uniformly distributed across all the infiltration routes.

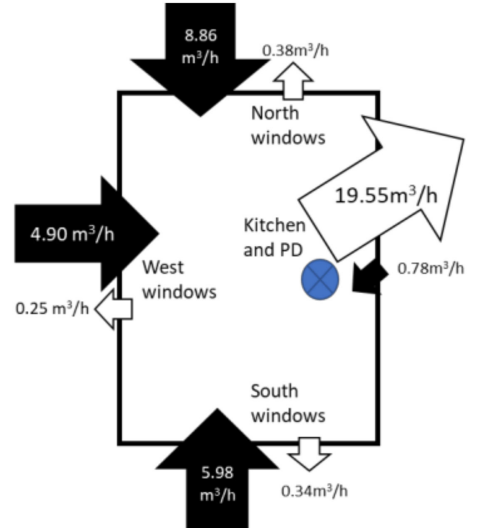

Average infiltration rate in C-201

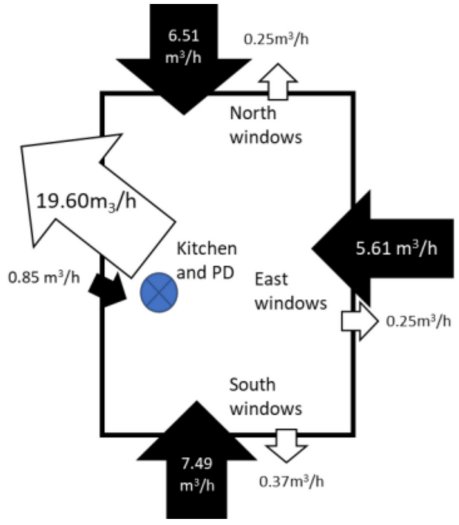

Average infiltration rate in C-202

Figure 10. Infiltration rate through each crack in C-201 and C-202.

\section{Discussion}

Even while measuring the same case at the same location of the same household, the measurement values were different during the blower door test periods. This is because the outdoor wind speed is different over time. Therefore, all the required measurements should be completed in a short time.

The ACHn obtained using the leakage-infiltration ratio N developed by the LBL was compared with the ACHn obtained in this study. When ACHn was obtained using the LBL method, it was calculated by dividing the ACH50 obtained by the blower door test by the leakage-infiltration ratio $\mathrm{N}=20$, which is a value commonly used in Korea. If a building is moved to another city, and blower door tests are implemented in the building again, the ACH50 value of the building should theoretically be the same in both cities. However, ACHn, infiltration in the natural state, would be different depending on the wind speed and direction of the region. The ACH50 value measured in C-201 using the blower door test at $50 \mathrm{~Pa}$ was 6.14, and the ACH50 value for C-202 was 8.07. If ACH50 is divided by 
$\mathrm{N}=20$, as suggested by the LBL, the calculated ACHn value becomes $0.31 \mathrm{ACHn}$ for C-201 and $0.40 \mathrm{ACHn}$ for $\mathrm{C}-202$.

The leakage-infiltration ratio $\mathrm{N}$ was calculated using EnergyPlus to convert $\mathrm{ACH} 50$ to the ACHn value. For C-201, the minimum and maximum values were calculated as 36 and 47 , respectively. For C-202, the minimum and maximum values were 42 and 89 , respectively. Because the number of measured households is small, the calculated leakage-infiltration ratio is not statistically effective. However, the leakage-infiltration ratio $\mathrm{N}$, suggested by the LBL, was different from that derived from measurement and simulation. This is presumed to be because of the difference in the housing conditions. In the US, detached houses are the predominant type of residential houses, and in Korea, high-rise apartments are predominant. For the apartment house measured in this study, the ACHn value was calculated to be $0.1 \sim 0.2$, even though the measured ACH50 value was 6-8. The ACHn value is comparable to the level of infiltration in modern commercial buildings.

To investigate how ACHn changes when a building with the same ACH50 is moved to other cities, the infiltration rates for C-201 in several cities were calculated through simulations. In addition, the results were compared to the values calculated using the LBL method, as listed in Table 3. The analysis was conducted for Seoul, which has the largest population in Korea, Sejong, in which the original building is located, and Jeju, which is the warmest and has the highest wind speed in Korea.

Table 3. Variation of the infiltration rate and leakage-infiltration ratio with the locations.

\begin{tabular}{ccccc}
\hline Location & $\begin{array}{c}\text { Simulation } \\
\text { (ACHn) }\end{array}$ & $\begin{array}{c}\text { LBL Method } \\
\text { (ACHn) }\end{array}$ & $\begin{array}{c}\text { Difference } \\
\text { (\%) }\end{array}$ & $\begin{array}{c}\text { Calculated } \\
\text { Leakage-Infiltration Ratio }\end{array}$ \\
\hline Sejong & 0.158 & 0.307 & 94 & 39 \\
Seoul & 0.202 & 0.307 & 52 & 30 \\
Jeju & 0.234 & 0.307 & 31 & 26 \\
\hline
\end{tabular}

The infiltration rate calculated using Jeju climate data has a minimum value of $0.199 \mathrm{ACHn}$, a maximum value of $0.250 \mathrm{ACHn}$, and an average value of $0.234 \mathrm{ACHn}$. They are 1.5 times larger than those calculated using Sejong climate data. Because the $\mathrm{ACH} 50$ value is the same regardless of the region, the average leakage-infiltration ratio for this building should be 26 if the same building is built in Jeju. If the building is built in Seoul, the average infiltration rate becomes $0.202 \mathrm{ACHn}$, and the calculated leakage-infiltration ratio becomes 30. For Sejong, the calculated leakage-infiltration ratio becomes 39. As listed in Table 3, the leakage-infiltration ratio $\mathrm{N}=20$ suggested by the LBL shows a significant difference from those derived from measurements and simulations. The calculated leakageinfiltration ratio $\mathrm{N}$ for various cities in Korea varies from 26 to 39 . To determine the natural ventilation $\mathrm{ACHn}$ through the blower door test, the relationship between $\mathrm{ACH} 50$ and ACHn should be determined. Therefore, a statistically proven leakage-infiltration ratio $\mathrm{N}$ that fits the domestic situation through actual measurements from various apartments is required.

Through measurement and analysis, it was found that the households in an apartment house have similar infiltration routes; however, the infiltration performance of each infiltration route is different. If the infiltration routes of the representative household are investigated in the preliminary test, the infiltration performance of each household can be estimated by performing a blower door test on the infiltration routes of each household. Through this process, the infiltration characteristics of each apartment can be identified, and the measurement time is expected to be reduced.

The actual measured weather data were not used in the analysis. Instead, the weather file, which are statistically processed for a standard year, were used in the analysis. The raw weather data used for making the climate data are measured at a bare ground, such as an airport, without any obstacles around it. Therefore, it shows the maximum wind speed in that area. Therefore, the ACHn value found in this analysis would be the theoretical maximum $\mathrm{ACHn}$ in the region. 


\section{Conclusions}

An experiment was conducted to measure the infiltration rates using blower door tests in two households in an apartment house built in 2018. Infiltration routes of the two households were investigated through a preliminary experiment. In the main measurement, data were obtained to determine the infiltration performance through each infiltration route using blower door tests. After determining the fluid coefficient $C$ and pressure exponent $n$ for each infiltration route through analysis using experimental data, the infiltration rates (ACHn) of the households were calculated using EnergyPlus. The average infiltration rate for C-201 was calculated to be $0.158 \mathrm{ACHn}$, and the average infiltration rate for C-202 was the same as that for C-201.

The changes in the infiltration rates of the buildings with the same ACH50 based on the region were investigated using simulation. This calculation was conducted under the assumption that the ACH50 is measured equally everywhere unless the altitude is different. The calculation was performed for Seoul, which has the largest population, and Jeju, which has the highest wind speed in Korea. The simulation results were compared with the calculation result obtained using the leakage-infiltration ratio suggested by the LBL. When the leakage infiltration $\mathrm{N}$ is used conservatively in Korea, $\mathrm{N}=20$ is the generally used value. From this study, it can be understood that, leakage-infiltration ratios need to be developed for each city to replace the existing leakage infiltration because the variation in the leakage infiltration of various regions is large, and there is a large difference between the leakage infiltration suggested by the LBL and those calculated in this study.

In this study, a method to estimate the average infiltration rate of an apartment house was suggested using blower door tests and a simulation program. According to the measurement, two households had the same infiltration routes; however, there was a difference in the infiltration performance of each route. The first step in determining the infiltration rate of an apartment house is to investigate the infiltration route through a preliminary measurement in a standard household of the apartment house. The next step is to investigate the infiltration performance of each infiltration route using blower door tests in other households in the apartment house. In the last step, the average infiltration rate can be calculated using a simulation. Using this process, the theoretical maximum average infiltration rate of the entire apartment can be measured in a short time. If statistically sufficient data are obtained by performing an infiltration analysis in various apartments, the theoretical minimum leakage-infiltration ratio $\mathrm{N}$ values suitable for the local situation of Korean apartments can be determined through this process.

Author Contributions: Conceptualization, methodology, software, formal analysis, resources, writing-original draft preparation, writing-review and editing, visualization, J.M.; validation, investigation, data curation, J.M.; J.L.; supervision, project administration, funding acquisition, M.K. All authors have read and agreed to the published version of the manuscript.

Funding: This work was supported by the Korea Institute of Energy Technology Evaluation and Planning (KETEP) and the Ministry of Trade, Industry, and Energy (MOTIE) of the Republic of Korea (No. 20172010000370).

Data Availability Statement: The data presented in this study are available on request from the corresponding author. The data are not publicly available due to the data security maintenance of LH.

Conflicts of Interest: The authors declare no conflict of interest.

\section{References}

1. Kang, K.N.; Lee, S.W.; Lee, E.J.; Park, M.J.; Lim, J.H.; Cho, B.R.; Lee, J.C. Just ACH50 Divided by 20?-Concentrated on a Residential Building. In Proceedings of the 2015 SAREK Summer Annu. Conf, Yongpyung, Korea, 24-26 June 2015; pp. 435-438.

2. Klems, J.H. Methods of estimating air infiltration through windows. Energy Build. 1983, 5, 243-252. [CrossRef]

3. Sherman, M.H.; Modera, M.P. Infiltration Using the LBL Infiltration Model. Meas. Air Leakage Perform. Build. 1986, 904, $325-347$.

4. Persily, A.K.; Linteris, G.T. A Comparison of Measured and Predicted Infiltration Rates. Ashrae Trans. 1983, 89, 183-200. 
5. Jokisalo, J.; Kalamees, T.; Kurnitski, J.; Eskola, L.; Jokiranta, K.; Vinha, J. A comparison of measured and simulated air pressure conditions of a detached house in a cold climate. J. Build. Phys. 2008, 32, 67-89. [CrossRef]

6. Sinnott, D.; Dyer, M. Airtightness field data for dwellings in Ireland. Build. Environ. 2012, 51, 269-275. [CrossRef]

7. Sherman, M.H.; Matson, N. Airtightness of New U.S. Houses: A Preliminary Report; Ernest Orlando Lawrence Berkeley National Laboratory: Berkeley, CA, USA, 2002.

8. Feijo-Munoz, J.; Gonzalez-Lezcano, R.A.; Poza-Casado, I.; Angel Padilla-Marcos, M.; Meiss, A. Airtightness of residential buildings in the continental area of Spain. Build. Environ. 2019, 148, 299-308. [CrossRef]

9. Jessica, F.A.; Samuel, D.A.; Juan, J.S.; Suarez, R. Predictive models for airtightness in social housing in a Mediterranean region. Sustain. Cities Soc. 2019, 51, 101695.

10. Johnston, D.; Miles-Shenton, D. The airtightness and air leakage characteristics of new UK holiday homes. Build. Serv. Eng. Res. Technol. 2017, 39, 343-361. [CrossRef]

11. Martín-Garín, A.; Millán-García, J.A.; Hidalgo-Betanzos, J.M.; Hernández-Minguillón, R.J.; Bderrahmane, B. Airtightness Analysis of the Built Heritage-Field Measurements of Nineteenth Century Buildings through Blower Door Tests. Energies 2020, $13,6727$. [CrossRef]

12. Khemet, D.; Richman, R. A univariate and multiple linear regression analysis on a national fan (de) pressurization testing database to predict airtightness in houses. Build. Environ. 2018, 146, 88-97. [CrossRef]

13. Chan, W.R.; Nazaroff, W.W.; Price, P.N.; Sohn, M.D.; Gadgil, A.J. Analyzing a database of residential air leakage in the United States. Atmos. Environ. 2005, 39, 3445-3455. [CrossRef]

14. Shi, S.; Chen, C.; Zhao, B. Air infiltration rate distributions of residences in Beijing. Build. Environ. 2015, 92, 528-537. [CrossRef]

15. Salehi, A.; Torres, I.; Ramos, A. Assessment of ventilation effectiveness in exiting residential building in Mediterranean countries: Case study, existing residential building in Portugal. Sustain. Cities Soc. 2017, 32, 496-507. [CrossRef]

16. Cho, J.H. Measurements of the Dwelling Unit Airtightness in High-rise Residential Buildings. J. Archit. Inst. Korea 2010, 26, 334-337.

17. Lee, Y.K.; Shin, C.U. The Air Leakage Characteristics and Airtightness Performance of a Newly Built Apartment. Soc. Air-Cond. Refrig. Eng. Korea 2013, 25, 606-611.

18. Yoon, J.O. Field Measurement of Infiltration in New Apartments using De-pressurization Method. Korea Inst. Ecol. Archit. Environ. 2013, 13, 27-32.

19. Undram, M.; Song, D.S.; Kim, J.U. A Review of the Test Methods for Air-tightness Performance of Building Components Using the Blower Door System. Soc. Air-Cond. Refrig. Eng. Korea 2019, 32, 216-226.

20. Kim, S.C.; Yoon, J.H.; Shin, W.C.; Kim, S.S.; Lee, H.J. A Study on the Measurement of Airtightness Performance of Multi House with High Levels of Airtight Construction. Korea Inst. Ecol. Archit. Environ. 2011, 11, 3-6.

21. Hult, E.L.; Sherman, M.H.; Walker, I.S. Blower-door techniques for measuring interzonal leakage: A Preliminary Report; Ernest Orlando Lawrence Berkeley National Laboratory: Berkeley, CA, USA, 2013.

22. Hult, E.L.; Dickerhoff, D.J.; Price, P.N. Measurement Methods to Determine Air Leakage between Adjacent Zones: A Preliminary Report; Ernest Orlando Lawrence Berkeley National Laboratory: Berkeley, CA, USA, 2012. 